\title{
Role of GABAergic Inhibition in Shaping Odor-Evoked Spatiotemporal Patterns in the Drosophila Antennal Lobe
}

\author{
Rachel I. Wilson ${ }^{1,2}$ and Gilles Laurent ${ }^{2}$ \\ ${ }^{1}$ Department of Neurobiology, Harvard Medical School, Boston, Massachusetts 02115, and 2Division of Biology 139-74, California Institute of Technology, \\ Pasadena, California 92115
}

\begin{abstract}
Drosophila olfactory receptor neurons project to the antennal lobe, the insect analog of the mammalian olfactory bulb. GABAergic synaptic inhibition is thought to play a critical role in olfactory processing in the antennal lobe and olfactory bulb. However, the properties of GABAergic neurons and the cellular effects of GABA have not been described in Drosophila, an important model organism for olfaction research. We have used whole-cell patch-clamp recording, pharmacology, immunohistochemistry, and genetic markers to investigate how GABAergic inhibition affects olfactory processing in the Drosophila antennal lobe. We show that many axonless local neurons (LNs) in the adult antennal lobe are GABAergic. GABA hyperpolarizes antennal lobe projection neurons (PNs) via two distinct conductances, blocked by a $\mathrm{GABA}_{\mathrm{A}}$ - and $\mathrm{GABA}_{\mathrm{B}}$-type antagonist, respectively. Whereas $\mathrm{GABA}_{\mathrm{A}}$ receptors shape $\mathrm{PN}$ odor responses during the early phase of odor responses, $\mathrm{GABA}_{\mathrm{B}}$ receptors mediate odor-evoked inhibition on longer time scales. The patterns of odor-evoked $\mathrm{GABA}_{\mathrm{B}}$-mediated inhibition differ across glomeruli and across odors. Finally, we show that LNs display broad but diverse morphologies and odor preferences, suggesting a cellular basis for odor- and glomerulus-dependent patterns of inhibition. Together, these results are consistent with a model in which odors elicit stimulus-specific spatial patterns of GABA release, and as a result, GABAergic inhibition increases the degree of difference between the neural representations of different odors.
\end{abstract}

Key words: olfactory; antennal lobe; $\mathrm{GABA} ; \mathrm{GABA}_{\mathrm{B}}$ receptor; synaptic transmission; interneurons

\section{Introduction}

Smell begins when odor molecules interact with olfactory receptor neurons (ORNs). ORNs then project to the brain following anatomical rules common to species as evolutionarily distant as flies and rodents. Briefly, the odor sensitivity of a particular ORN is specified by the expression of a single olfactory receptor gene (Ressler et al., 1993; Vassar et al., 1993; Vosshall et al., 1999; Hallem et al., 2004) (but see Goldman et al., 2005). All the ORNs that express a particular receptor send their axons to the same glomeruli in the brain (Ressler et al., 1994; Vassar et al., 1994; Vosshall et al., 2000). There, ORNs make synapses with secondorder neurons [mitral cells (in vertebrates) or projection neurons (in insects)].

What happens when signals reach these second-order olfactory neurons is determined by complex local circuitry. One obstacle to understanding this circuitry is the sheer number of input channels in the mammalian olfactory system. The rat olfactory bulb contains $\sim 1000$ glomeruli; in contrast, the Drosophila antennal lobe contains just $\sim 40$ glomeruli. This, along with the

Received May 23, 2005; revised Aug. 24, 2005; accepted Aug. 25, 2005.

R.I.W. is supported by a Smith Family Foundation New Investigator Award, a Loreen Arbus Scholarship in Neuroscience at Harvard Medical School, and a Pew Scholarship in Biomedical Sciences. G.L. is supported by grants from the National Institute on Deafness and Other Communication Disorders and the National Science Foundation. We thank R. Stocker and L. Luo for flies, E. Buchner for nc 82 antibody, and G. C. Turner for many helpful discussions and advice on GABA immunostaining. Confocal microscopy was assisted by the Harvard Center for Neurodegeneration and Repair and the Caltech Biological Imaging Facility.

Correspondence should be addressed to Rachel Wilson at the above address. E-mail: rachel_ wilson@hms.harvard.edu.

DOI:10.1523/JNEUROSCI.2070-05.2005

Copyright $\odot 2005$ Society for Neuroscience $\quad$ 0270-6474/05/259069-11\$15.00/0 genetic advantages of Drosophila, makes the fruit fly a useful model for investigating olfactory processing.

A given odor excites many Drosophila antennal lobe projection neurons (PNs) but inhibits others (Wilson et al., 2004). These odor-evoked inhibitory epochs can last from $\sim 100 \mathrm{~ms}$ to several seconds. Similar odor-evoked inhibition has also been observed in other insects and in olfactory bulb mitral cells (Macrides and Chorover, 1972; Hamilton and Kauer, 1989; Kanzaki et al., 1989; Wellis et al., 1989; Buonviso et al., 1992; MacLeod and Laurent, 1996; Friedrich and Laurent, 2001; Luo and Katz, 2001; Margrie et al., 2001; Cang and Isaacson, 2003). Some odor responses of mitral cells and PNs are purely inhibitory. Other responses are multiphasic, in which an inhibitory epoch follows or precedes an excitatory epoch. These temporal patterns are cell and odor dependent and have been proposed to encode information about the stimulus (Laurent and Davidowitz, 1994; Stopfer et al., 1997). However, the mechanism of these "slow" patterns is not fully understood.

One possibility is that inhibitory epochs represent periods when principal neurons are synaptically inhibited by GABAergic local neurons (LNs). GABA-immunoreactive LNs are present in the adult antennal lobe of several species (Hoskins et al., 1986; Malun, 1991; Leitch and Laurent, 1996; Bicker, 1999) and in the larval Drosophila antennal lobe (Python and Stocker, 2002). Antennal lobe LNs can synaptically inhibit PNs (Christensen et al., 1993; MacLeod and Laurent, 1996), and the antennal lobe is strongly immunoreactive for $\mathrm{GABA}_{\mathrm{A}}$ receptors (Harrison et al., 1996). However, $\mathrm{GABA}_{\mathrm{A}}$ antagonists do not block odor-evoked slow inhibition or slow temporal patterns in PNs (MacLeod and 
Laurent, 1996; Christensen et al., 1998; Wilson et al., 2004). Therefore, these inhibitory epochs have been hypothesized to reflect a metabotropic conductance (Bazhenov et al., 2001) or the action of a different inhibitory neurotransmitter (Sachse and Galizia, 2002). Alternatively, inhibition of PNs could be caused by inhibition of ORNs (Dobritsa et al., 2003).

Here, we investigate the mechanisms of odor-evoked inhibition in PNs. We confirm that many Drosophila antennal lobe LNs are GABAergic. GABA receptors contribute to odor-evoked inhibition of PNs on both fast and slow time scales, and GABAmediated slow inhibition increases the diversity of odor-evoked responses among PNs. This is consistent with models that invoke GABAergic inhibition to increase the discriminability of olfactory representations.

\section{Materials and Methods}

Fly stocks. Flies were reared on standard cornmeal agar medium. Except where otherwise noted, flies were wild type (Canton-S). GH146-Gal4 and c739-Gal4 flies were a gift from L. Luo (Stanford University, Stanford, CA). GH298-Gal4,UAS-CD8GFP/TM6bHu flies were a gift from R. Stocker (University of Fribourg, Fribourg, Switzerland). All experimental animals were adult females, 3-10 d after eclosion.

Immunocytochemistry. For anti-GABA staining of brains that also express a CD8GFP cell marker, brains were fixed for $15 \mathrm{~min}$ in $5 \%$ formaldehyde in PBS, rinsed with PBS, and blocked in 5\% normal goat serum/ PBST $(0.2 \%$ Triton X-100 in PBS) for $20 \mathrm{~min}$. Brains were incubated in 1:100 rabbit anti-GABA antibody (catalog \#A2052; Sigma, St. Louis, $\mathrm{MO}$ ) and 1:25 rat anti-CD8 antibody (Caltag Laboratories, Burlingame, $\mathrm{CA}$ ) at $4^{\circ} \mathrm{C}$ for $2 \mathrm{~d}$. After washing for $1 \mathrm{~h}$ in several changes of PBST, brains were incubated with 1:250 goat anti-rabbit:Alexa Fluor 568 and 1:250 goat anti-rat:Alexa Fluor 488 (Molecular Probes, Eugene, OR) for $2 \mathrm{~d}$ at $4^{\circ} \mathrm{C}$. To visualize biocytin-filled neurons and glomerular boundaries, brains were incubated in 1:10 mouse nc82 antibody (gift from E. Buchner, University of Würzburg, Würzburg, Germany) for $24 \mathrm{~h}$ at $4^{\circ} \mathrm{C}$ and then washed for $30 \mathrm{~min}$ in several changes of PBST before incubation with 1:1000 goat anti-mouse:Alexa Fluor 568 and 1:1000 streptavidin: Alexa Fluor 488 for $24 \mathrm{~h}$ at $4^{\circ} \mathrm{C}$. After incubation with secondary detection reagents, brains were washed for $20 \mathrm{~min}$ in PBST and mounted in Vectashield on a slide flanked by two \#1 coverslips. Confocal fluorescence microscopy was performed on a Zeiss (Oberkochen, Germany) LSM 510 using a $63 \times$ oil-immersion objective. Biocytin fills were used not only to visualize LN morphology (see Fig. 5) but also to identify which glomerulus a PN innervated (see Fig. 4).

Image analysis. Confocal Z-stacks were acquired in $1 \mu \mathrm{m}$ slices and imported into NIH ImageJ for analysis. Counts of green fluorescent protein-positive $(\mathrm{GFP}+)$ and GABA+ cells (see Fig. 1) were performed using the Cell Counter plugin (K. De Vos, http://rsb.info.nih.gov/ij/ plugins/cell-counter.html). LN innervation density (see Fig. 5C) was computed for selected glomeruli using the Measure Stack plugin (B. Dougherty, http://www.optinav.com/ImageJplugins/list.htm). Glomerular boundaries were defined according to the nc82 signal by drawing a region of interest (ROI) every three slices and interpolating through the stack. Mean pixel value was computed for this three-dimensional ROI.

Electrophysiology. Flies were prepared for in vivo whole-cell patchclamp recording as described previously (Wilson et al., 2004). The saline composition was as follows (in $\mathrm{mm}$ ): $103 \mathrm{NaCl}, 3 \mathrm{KCl}, 5$ $\mathrm{N}$-tris(hydroxymethyl) methyl-2-aminoethane-sulfonic acid, 10 trehalose, 10 glucose, 2 sucrose, $26 \mathrm{NaHCO}_{3}, 1 \mathrm{NaH}_{2} \mathrm{PO}_{4}, 1.5 \mathrm{CaCl}_{2}$, and 4 $\mathrm{MgCl}_{2}$, adjusted to $275 \mathrm{mOsm}, \mathrm{pH}$ equilibrated near 7.3 when bubbled. The saline was bubbled with $95 \% \mathrm{O}_{2} / 5 \% \mathrm{CO}_{2}$ and perfused continuously over the preparation at $2 \mathrm{ml} / \mathrm{min}$. Recordings were obtained from $\mathrm{PN}$ or LN somata under visual control using an Axioskop FS-1 (Zeiss) or Olympus (Melville, NY) BX51F with infrared-differential interference contrast (IR-DIC) optics and a $40 \times$ water-immersion objective. One PN or LN was recorded per fly. PNs and LNs are readily distinguishable from each other based on their very different intrinsic properties (Wilson et al., 2004). In most cases, we also confirmed the identity of each recorded cell by visualizing its biocytin fill post hoc. In every case, cells with small-amplitude action potentials ( $<12 \mathrm{mV}$ in amplitude) were PNs, whereas cells with large action potentials (always $>40 \mathrm{mV}$ ) were confirmed as LNs.

Patch-clamp electrodes (5-7 M $\Omega$ ) were filled with a solution composed of the following (in $\mathrm{mM}$ ): 140 potassium aspartate, 10 HEPES, 1 $\mathrm{KCl}, 4 \mathrm{MgATP}, 0.5 \mathrm{Na}_{3} \mathrm{GTP}$, and 1 EGTA, pH 7.3, adjusted to 265 mOsm. In most experiments, $0.5 \%$ biocytin hydrazide was added to the internal solution. This internal solution composition yielded a GABA reversal potential near $E_{\mathrm{Cl}}$ and a spike threshold near $-40 \mathrm{mV}$ (supplemental Fig. 1, available at www.jneurosci.org as supplemental material). In most cells, it was necessary to inject a small constant hyperpolarizing current $(0-30 \mathrm{pA})$, beginning immediately after break-in, to bring the membrane potential between -55 to $-60 \mathrm{mV}$; under these conditions, spontaneous spiking rates in LNs matched the rate observed in cellattached mode before break-in. Voltage was acquired in current-clamp mode, digitized at $10 \mathrm{kHz}$, and low-pass filtered at $5 \mathrm{kHz}$.

Pharmacology. For GABA iontophoresis experiments, pulled glass capillaries $(\sim 80 \mathrm{M} \Omega$ ) were filled with $250 \mathrm{~mm}$ GABA, pH 4.3 in water. GABA diffusion from the tip was controlled by applying a negative backing current $(0-5 \mathrm{nA})$ using a constant-current iontophoresis instrument (World Precision Instruments, Sarasota, FL). GABA was ejected by applying a brief positive ejection current ( $4-7 \mathrm{~ms}, 1000 \mathrm{nA}$ ) every $20 \mathrm{~s}$. Fine adjustment of the backing current was generally needed to achieve a response that was stable over time.

Antagonists were prepared as concentrated stock solutions; during an experiment, a measured volume of stock was added to the measured volume of saline in the reservoir of perfusate, resulting in a defined dilution producing the final concentration of the antagonist. All drug concentrations reported in the text are final concentrations. Picrotoxin was prepared as a $5 \mathrm{~mm}$ stock in $100 \mathrm{~mm} \mathrm{NaCl}$. Bicuculline methiodide was prepared as a $15 \mathrm{~mm}$ stock in $\mathrm{H}_{2} \mathrm{O}$ immediately before use. 3- $\mathrm{N}$-[1(3,4-dichlorophenyl)ethylamino)-2-hydroxypropyl cyclohexylmethyl phosphinic acid (CGP54626) was prepared as a $250 \mathrm{~mm}$ stock in DMSO. In some cells, CGP54626 caused an increase in the spontaneous spiking rate of the cell. In these cases, additional constant hyperpolarizing current was added to the current command to return the cell to its original spontaneous spiking rate before testing any more odors.

We tested the effect of CGP54626 on 11 cells. Each of these cells was tested with several odors, resulting in 46 cell-odor combinations. This entire dataset was used to construct the graph in Figure 4G. In Figure 3, $C$ and $D$, we omitted the five cell-odor combinations with the lowest peak odor-evoked spike rates, so that average control peak spike rates were similar for the CGP54626 and picrotoxin experiments. Including the omitted five data points in Figure 3 did not change our conclusions and did not alter the statistical significance our results.

Olfactory stimuli. In olfactory stimulation experiments, a constant stream of charcoal-filtered air $(2.15 \mathrm{~L} / \mathrm{min})$ was directed at the fly throughout the recording. For the experiments shown in Figures 3 and 4 , odors were placed undiluted in a vial. After a trigger, a three-way solenoid valve redirected $7 \%$ of the airstream through the headspace of the odor vial for $1 \mathrm{~s}$. Odors used in these experiments were pentyl acetate, methyl salicylate, benzaldehyde, ethyl 3-hydroxybutyrate, p-cresol, 2-heptanone, 1-hexanol, trans-2-hexenal, and 1-octen-3-ol. For the experiments shown in Figure 6 and supplemental Figure 2 (available at www.jneurosci.org as supplemental material), each of the seven test odors was diluted 100 -fold v/v in paraffin oil. The constant airstream speed was $2.2 \mathrm{~L} / \mathrm{min}$, and the stimulus trigger redirected $9 \%$ of the airstream through the headspace of the odor vial for $500 \mathrm{~ms}$. The odor stream rejoined the nonodor stream $16 \mathrm{~cm}$ from the end of the end of the delivery tube, which measured $3 \mathrm{~mm}$ in diameter. The end of the delivery tube was positioned $8 \mathrm{~mm}$ from the fly. Odor presentations (typically six trials per odor) were spaced $45-60 \mathrm{~s}$ apart.

\section{Results \\ Most antennal lobe local neurons defined by the GH298 marker are GABAergic}

As in the olfactory bulb, each glomerulus in the Drosophila antennal lobe contains four main classes of neurons: (1) the axon terminals of ORNs, (2) the dendrites of PNs that convey infor- 
mation from ORNs to higher brain centers, (3) neurites from LNs that interconnect glomeruli, and (4) the centrifugal axonal projections of neurons that relay information to the antennal lobe from higher brain centers (Stocker et al., 1990). Recent studies have illuminated the development, morphology, and physiology of Drosophila ORNs and PNs (Keller and Vosshall, 2003; Hallem and Carlson, 2004). Drosophila LNs, in contrast, have not received much attention. LNs have been noted in Golgiimpregnated antennal lobes (Stocker et al., 1990), but remarkably little is known about the number, morphology, and connectivity of these cells or about their impact on other antennal lobe neurons. If adult LNs are also GABAergic, and if GABA is inhibitory (as it is in other insects), then LNs could participate in sculpting the inhibitory epochs prominent in many $\mathrm{PN}$ odor responses. In the larval Drosophila antennal lobe, many LNs are immunopositive for GABA (Python and Stocker, 2002). In the adult, it has been shown that many somata around the antennal lobes express the GABA biosynthetic enzyme glutamic acid decarboxylase ( $\mathrm{Ng}$ et al., 2002).

We began by confirming that many adult Drosophila antennal LNs are GABAergic. Using confocal immunofluorescence microscopy with an anti-GABA antibody, we observed many GABA-positive somata in the vicinity of the antennal lobe neuropil (Fig. 1). To identify LNs, we used flies in which a large subpopulation of these cells are genetically labeled. In these flies (GAL4 enhancer trap line GH298), reporter gene activity labels a cluster of somata lateral to the antennal lobe neuropils. The neurites of these neurons collectively fill the antennal lobes, reminiscent of the morphology of LNs identified in Golgi impregnations (Stocker et al., 1997). When we made whole-cell patch-clamp recordings from the somata of GFP-positive cells in GH298GAL4,UAS-CD8GFP flies, we observed intrinsic properties characteristic of LNs $(n=7)$, namely high input resistances (1-4G $\Omega$ ) and action potentials with amplitude $>40 \mathrm{mV}$ (Wilson et al., 2004). We also confirmed with single-cell biocytin fills that these GFP-positive neurons were indeed LNs $(n=3)$. When we visualized GH298-GAL4,UAS-CD8GFP brains stained for GABA using dual-channel confocal microscopy, we found that most GFPpositive somata were also GABA positive $(29 \pm 1$ of $36 \pm 2 \mathrm{GFP}+$ somata were $\mathrm{GABA}+; n=4$ brains) (Fig. $1 A$ ). About one-fifth of the GFP-positive somata did not stain for GABA ( $7 \pm 1$ cells per antennal lobe). These neurons may contain a different neurotransmitter, or our staining may not have been sensitive enough to detect low levels of GABA. We also cannot presently exclude the possibility that these GABA-negative neurons are not LNs.

To confirm the specificity of our antibody, we also examined an enhancer-trap line that labels a large subpopulation of PNs (GH146-GAL4,UAS-CD8GFP) (Stocker et al., 1997). Most PNs are thought to be cholinergic, because they express choline acetyltransferase and make excitatory synapses onto LNs (Python and Stocker, 2002; Wilson et al., 2004). We observed that all of the PNs in the dorsal and lateral clusters ( $\sim 90$ cells) were GABA negative (Fig. $1 B$ ). A handful of GFP-positive neurons ventral and slightly lateral to the antennal lobes were GABA positive ( $6 \pm$ 0.4 cells per antennal lobe; $n=5$ brains) (Fig. $1 B$, arrow). These may correspond to the multiglomerular PNs identified in clonal studies of the antennal lobe (Marin et al., 2002).

\section{GABA hyperpolarizes projection neurons via two} pharmacologically distinct conductances

Next, we asked whether GABA hyperpolarizes antennal lobe neurons in the adult brain. The effect of GABA on Drosophila neurons has until now only been described in embryonic or larval

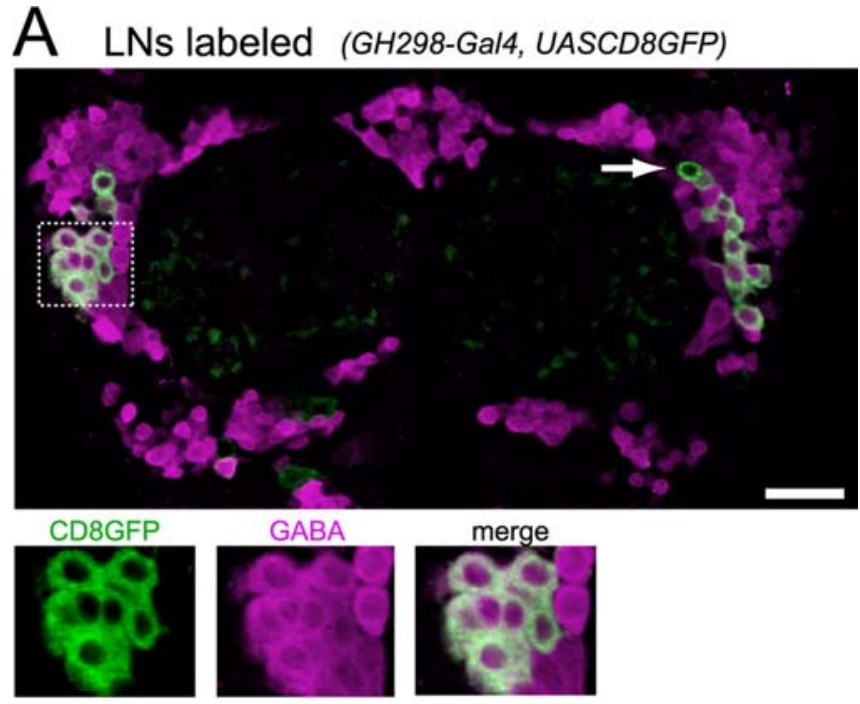

\section{B PNs labeled (GH146-Gal4, UASCD8GFP)}

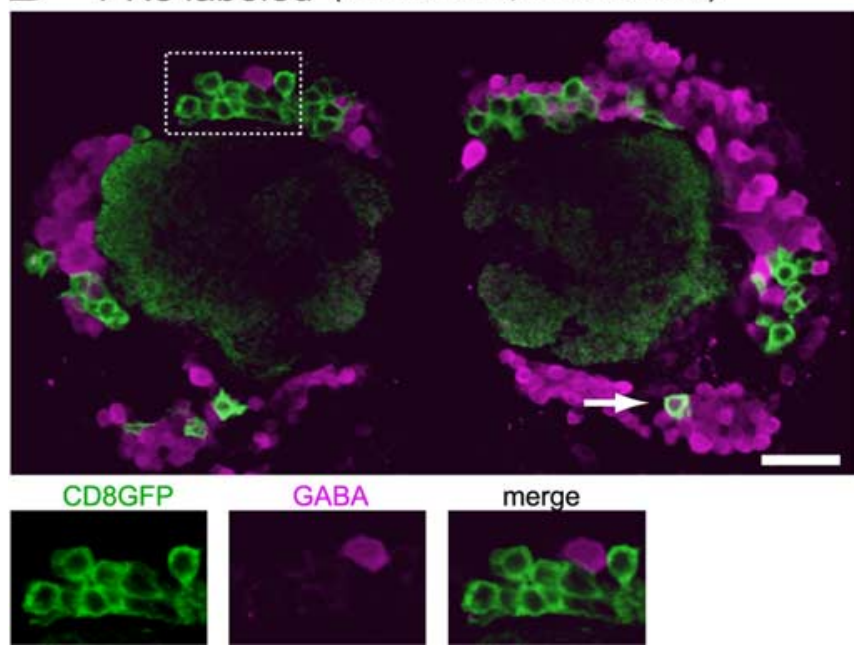

Figure 1. Many antennal lobe LNs are GABAergic, but most PNs are not. $A$, Projection of a 2 $\mu \mathrm{m}$ confocal Z-stack through the center of both antennal lobes. GABA (magenta) colocalizes with CD8GFP (green) driven by GH298-Gal4, which targets a subpopulation of LNs. A minority of GFP-positive cells are GABA negative (arrow). The box outlined with a dotted line is enlarged below to show each channel individually. In all images, dorsal is up and ventral is down. B, GABA does not colocalize with CD8GFP driven by GH146-Gal4, which labels a subpopulation of PNs. All PNs are GABA negative, with the exception of approximately six ventral PNs (arrow). Scale bars, $20 \mu \mathrm{m}$.

preparations (Rohrbough and Broadie, 2002; Lee et al., 2003; Su and O'Dowd, 2003). We immobilized whole adult flies and microdissected away the dorsal head cuticle and perineural sheath to visualize the antennal lobes from the dorsal side. In this in vivo preparation, individual neurons can be identified for patchclamp recording using IR-DIC optics (Wilson et al., 2004). We used local microiontophoresis to apply brief pulses of GABA to the cell body of the neuron we were recording from. A nicotinic antagonist (D-tubocurarine; $50 \mu \mathrm{M}$ ) was included in the saline during the GABA iontophoresis experiments.

Because LNs fire action potentials readily observable from somata in cell-attached mode, we first tested the effect of GABA on the spontaneous firing rate of LNs extracellularly, without disturbing intracellular ion concentrations. GABA consistently inhibited spontaneous firing in these neurons, from an initial rate of $2.3 \pm 0.2$ to $0 \pm 0$ spikes/s $(n=12)$. After rupturing the patch, the effect of GABA on spike rate was similar (Fig. $2 A$ ). In whole- 
cell mode, when the cell was held at threshold $(-39 \pm 1 \mathrm{mV})$, a $1 \mathrm{~s}$ pulse of GABA hyperpolarized the soma to $-56 \pm$ $2 \mathrm{mV}(n=10)$ and consistently inhibited spiking from an initial rate of $2.2 \pm 0.3$ to $0 \pm 0$ spikes/s.

Next, we examined the pharmacology of GABA-gated conductances in both LNs and PNs. In these experiments, brief pulses of GABA (4-7 ms) were microiontophoresed into the antennal lobe neuropil, producing IPSP-like hyperpolarizations in LNs and PNs (Fig. 2 B). Picrotoxin $(250 \mu \mathrm{M})$ blocked $98 \pm 3 \%$ of this hyperpolarization in LNs $(n=6)$ (Fig. $2 B)$. This implies that GABA gates an ionotropic conductance in LNs. Because ionotropic GABA receptor subunits cloned from Drosophila are most homologous to vertebrate $\mathrm{GABA}_{\mathrm{A}}$ receptor subunits (ffrenchConstant et al., 1991; Henderson et al., 1993; Harvey et al., 1994), we will refer to this picrotoxin-sensitive conductance as $\mathrm{GABA}_{\mathrm{A}}$-type, although the pharmacology of ionotropic insect receptors does not fit neatly into the vertebrate $\mathrm{GABA}_{\mathrm{A}} / \mathrm{GABA}_{\mathrm{C}}$ classification (Hosie et al., 1997).

In contrast, picrotoxin blocked less than one-half $(46 \pm 5 \%)$ of the GABAgated hyperpolarization in PNs $(n=14)$ (Fig. $2 B$ ). This implies that, in addition to $\mathrm{GABA}_{\mathrm{A}}$-type receptors, PNs express a GABA receptor absent from LNs. The diminished effectiveness of picrotoxin in PNs seemed unlikely to be caused by an insufficient dose of the antagonist. This is because $250 \mu \mathrm{M}$ is a relatively high dose of picrotoxin, much higher than that required to block $\mathrm{GABA}_{\mathrm{A}}$-type receptors in Drosophila (Rohrbough and Broadie, 2002). In separate experiments, we confirmed that just $1 \mu \mathrm{M}$ picrotoxin is sufficient to block $94 \pm 4 \%$ of the GABA-gated hyperpolarization in LNs $(n=4)$ (supplemental Fig. 3, available at www.jneurosci.org as supplemental material).

Three $\mathrm{GABA}_{\mathrm{A}}$ receptor subunits $(R D L$, $L C C H 3$, and $G R D$ ) have been cloned from the Drosophila genome. $\mathrm{GABA}_{\mathrm{A}}$ receptors may exist as homomers or heteromers. Whereas RDL homomers are blocked by picrotoxin, RDL/LCCH3 heteromers are insensitive to picrotoxin but blocked by bicuculline (Zhang et al., 1995; Hosie et al., 1997). Therefore, we tested whether GABA-gated conductances in antennal lobe neurons are sensitive to this antagonist. Bicuculline $(250 \mu \mathrm{M})$ substantially reduced the GABA-gated hyperpolarization in LNs (by $85 \pm 14 \% ; n=3$ ), consistent with the notion that this conductance is $\mathrm{GABA}_{\mathrm{A}}$-type. Incomplete block is likely attributable to the low potency of bicuculline at invertebrate $\mathrm{GABA}_{\mathrm{A}}$ receptors (Murphy and Wann, 1988; Sattelle et al., 1988; Hollins and McClintock, 2000). In contrast, bicuculbars represent SEM.

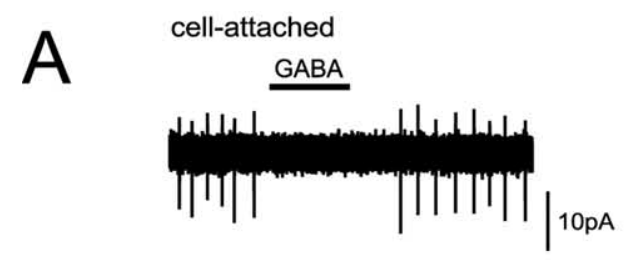

whole-cell
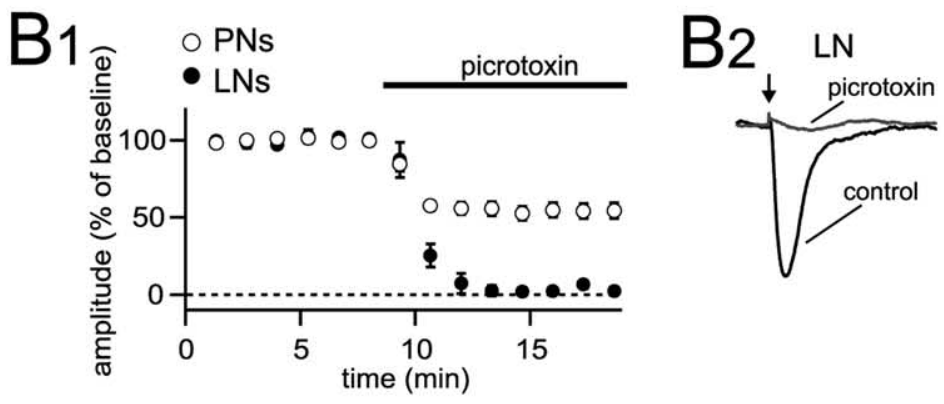

$20 \mathrm{mV}$
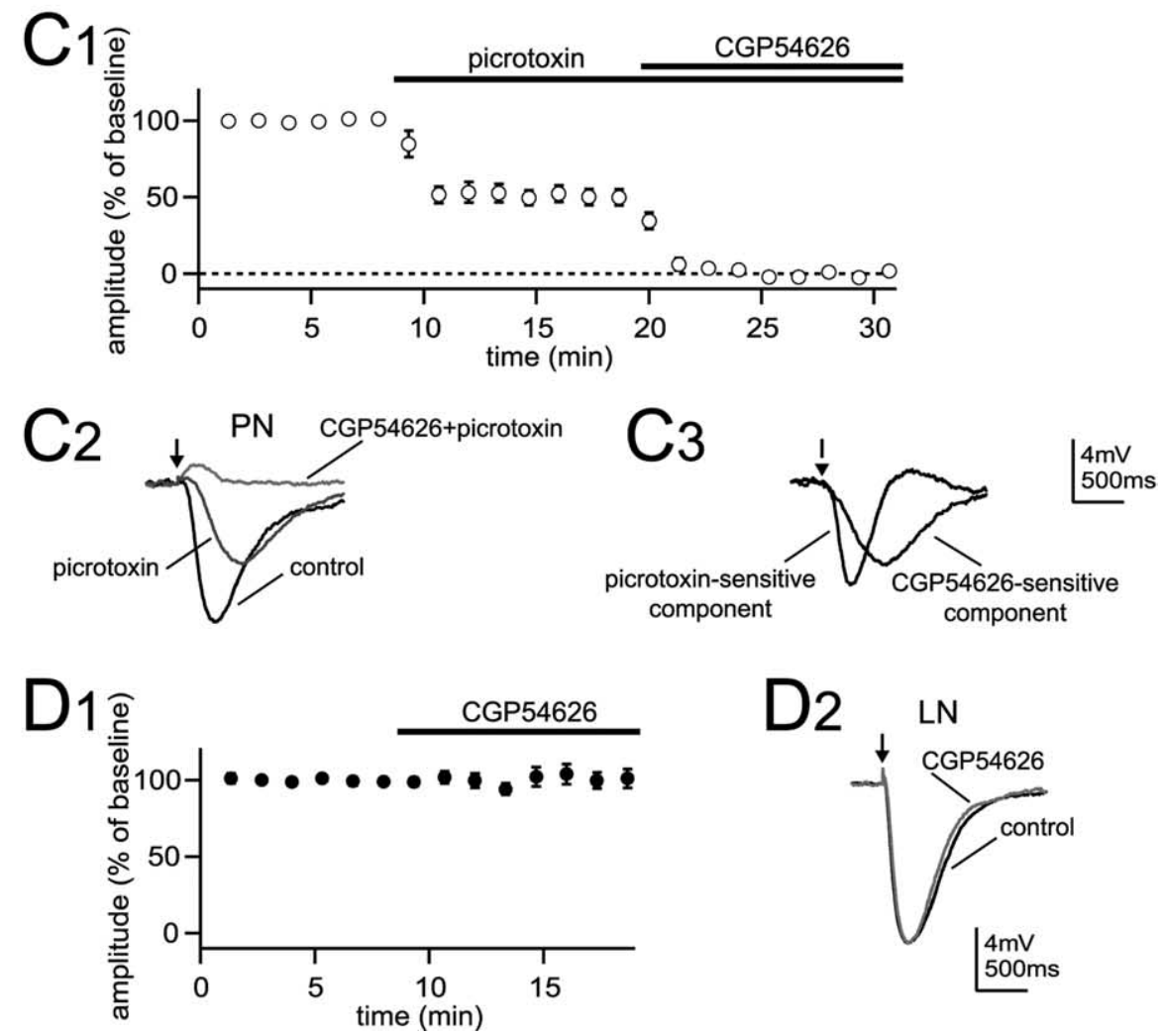

Figure 2. GABA hyperpolarizes antennal lobe neurons via both $G A B A_{A}$ and $G A B A_{B}$ receptors. $A, A 1$ s microiontophoretic pulse of GABA at the soma suppresses spontaneous spiking of an $L N$ recorded in cell-attached mode (left). GABA has a similar effect after rupturing the patch (right). B1, GABA was microiontophoresed periodically into the neuropil, and the amplitude of the GABAevoked hyperpolarization was monitored over time in whole-cell recordings. The graph plots mean \pm SEM hyperpolarization amplitude as a percentage of control. Picrotoxin blocked the GABA response in LNs but suppressed less than one-half of the GABA response in PNs. B2, Representative traces show GABA response before and after addition of picrotoxin in an LN (left) and a PN (right). The arrows mark GABA pulses. C1, CGP54626 blocks the picrotoxin-resistant GABA response in PNs. C2, Representative traces show GABA response in a PN before and after addition of picrotoxin and after addition of CGP54626. C3, Subtracted traces show the picrotoxin-sensitive component and CGP54626-sensitive component from traces in C2.D1, CGP54626 does not affect the GABA response in LNs. D2, Representative traces show the GABA response in an LN before and after addition of CGP54626. Error

line did not affect the picrotoxin-insensitive portion of the GABA response in PNs (amplitude in picrotoxin and bicuculline was $98 \pm 3 \%$ of picrotoxin alone; $n=3$; data not shown).

This suggested that the remaining GABA-gated conductance in PNs may not be mediated by $\mathrm{GABA}_{\mathrm{A}}$-type receptors. Consistent with this, the picrotoxin-resistant GABA conductance in 

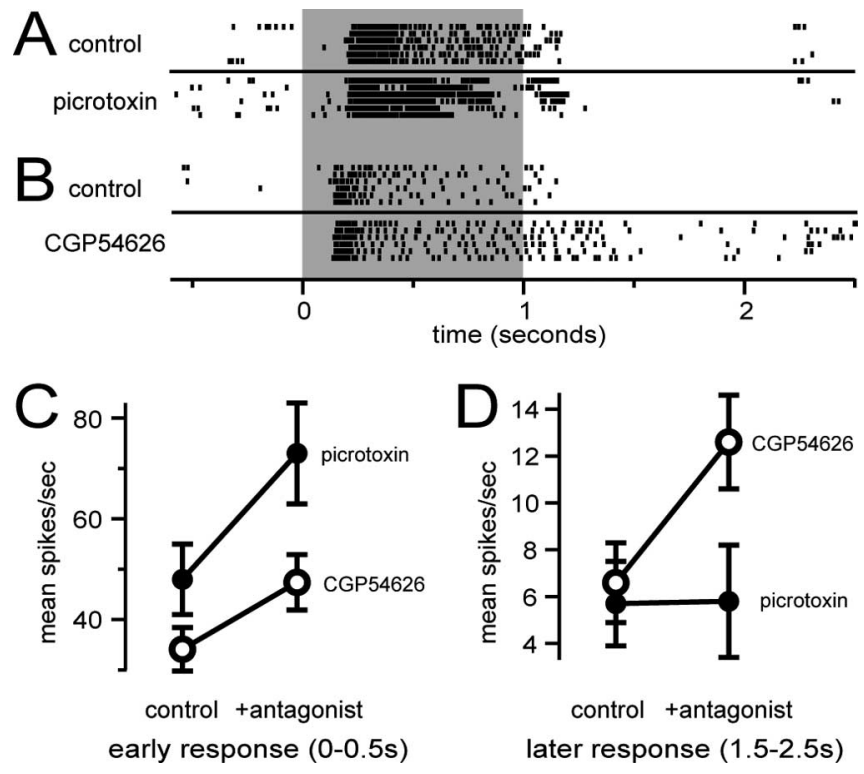

Figure 3. $\mathrm{GABA}_{\mathrm{B}}$ receptors contribute to long inhibitory epochs during $\mathrm{PN}$ odor responses. $\boldsymbol{A}$, Rasters show spikes in a PN during odor stimulation (gray bar; $1 \mathrm{~s}$ ). Each row represents a different trial. After adding picrotoxin, the number of spikes elicited in the first few hundred milliseconds after stimulus onset is increased, but the late inhibitory epoch is unaffected. $\boldsymbol{B}$, CGP54626 blocks the late inhibitory epoch in a PN odor response. C, Group data averaged over all cell-odor combinations (mean \pm SEM) show that both picrotoxin and (GP54626 increase PN spike rate during the first $500 \mathrm{~ms}$ of the odor response, although the effect of picrotoxin is stronger. D, CGP54626 also increases the odor-evoked PN spike rate later in the response, $1.5-2.5 \mathrm{~s}$ after stimulus onset, when picrotoxin has no effect. Error bars represent SEM.

PNs had slower kinetics than the picrotoxin-sensitive conductance (Fig. $2 B, C$, insets), possibly suggesting a metabotropic receptor. We next tested CGP54626, which antagonizes Drosophila $\mathrm{GABA}_{\mathrm{B}}$ receptors in heterologous cells (Mezler et al., 2001) and blocks the ability of GABA to suppress spontaneous calcium transients in cultured Drosophila neurons (Hamasaka et al., 2005). CGP54626 $(50 \mu \mathrm{M})$ rapidly and completely blocked the picrotoxin-resistant GABA response in PNs (by $97 \pm 2 \%$; $n=5$ ) (Fig. 2C). This drug did not affect the GABA-gated hyperpolarization in LNs (amplitude in CGP54626, $101 \pm 6 \%$ of control; $n=5$ ) (Fig. $2 D$ ), confirming its specificity at this concentration. Together, these results demonstrate that GABA inhibits PNs via two distinct conductances, one a $\mathrm{GABA}_{\mathrm{A}}$-type ionotropic receptor, the other a $\mathrm{GABA}_{\mathrm{B}}$-type metabotropic receptor. GABA inhibits $\mathrm{LNs}$ solely via a $\mathrm{GABA}_{\mathrm{A}}$-type conductance.

\section{$\mathrm{GABA}_{\mathrm{A}}$ and $\mathrm{GABA}_{\mathrm{B}}$ receptors shape odor-evoked activity on different time scales}

We observed that picrotoxin increases the number of spikes evoked in PNs during the first few hundred milliseconds after odor stimulus onset (Wilson et al., 2004). When an odor evokes a long (>300 ms) inhibitory epoch in a $\mathrm{PN}$, however, picrotoxin typically does not affect this inhibition (Wilson et al., 2004) (Fig. $3 A$ ). A similar result has been described in the locust and moth antennal lobe (MacLeod and Laurent, 1996; Christensen et al., 1998). Therefore, these odor-evoked silent periods are not mediated by $\mathrm{GABA}_{\mathrm{A}}$ receptors. If these inhibitory epochs are caused by GABAergic synaptic inhibition, they must involve pharmacologically distinct postsynaptic receptors, possibly $\mathrm{GABA}_{\mathrm{B}}$-type receptors (Bazhenov et al., 2001).

We tested whether $\mathrm{GABA}_{\mathrm{B}}$ receptors might contribute to odor-evoked prolonged inhibition in PNs. We recorded the re- sponse of a PN to several odors, added CGP54626 (50 $\mu \mathrm{M})$ to the saline perfusate, and repeated each odor. Averaged over all cellodor pairs, CGP54626 significantly increased the number of PN spikes in the first $500 \mathrm{~ms}$ of the odor response $\left(p<10^{-7}\right.$; paired $t$ test; $n=41 \mathrm{PN}$-odor combinations from $11 \mathrm{PNs}$ ) (Fig. $3 C$ ). This implies that $\mathrm{GABA}_{\mathrm{B}}$ receptors participate in modulating the peak odor-evoked spike rate in PNs. In this early epoch of the response, however, picrotoxin had an even greater disinhibitory effect ( $p<0.01 ; n=14 \mathrm{PN}$-odor combinations from five PNs; either 1 or $250 \mu \mathrm{M}$ picrotoxin with similar results) (Fig. $3 C$ ), suggesting that $\mathrm{GABA}_{\mathrm{A}}$ receptors may play an even larger role. In contrast, blocking $\mathrm{GABA}_{\mathrm{A}}$ receptors had no significant effect on the later phase of the odor response (1.5-2.5 s after stimulus onset; $p>0.9$ ) (Fig. $3 D$ ). In contrast, blocking $\mathrm{GABA}_{\mathrm{B}}$ receptors increased the odor-evoked spike rate during this late epoch $(p<$ $10^{-5}$ ) (Fig. $3 B, D$ ).

These results demonstrate that $\mathrm{GABA}_{\mathrm{A}}$ and $\mathrm{GABA}_{\mathrm{B}}$ receptors shape $\mathrm{PN}$ odor responses on different time scales. What could explain this difference? Part of the explanation likely involves the different kinetics of $\mathrm{GABA}_{\mathrm{A}}$ - and $\mathrm{GABA}_{\mathrm{B}}$-mediated currents (Fig. 2C3). The slower kinetics of $\mathrm{GABA}_{\mathrm{B}}$ receptors will tend to bias $\mathrm{GABA}_{\mathrm{B}}$ control toward the later portions of the response, although this alone is unlikely to explain the difference in time scales we observe. Desensitization of $\mathrm{GABA}_{\mathrm{A}}$ receptors may also limit their participation in late portions of the odor-evoked response (Celentano and Wong, 1994). Furthermore, postsynaptic $\mathrm{GABA}_{\mathrm{B}}$ receptors are thought to be localized outside the synaptic cleft, at least in the mammalian brain (Isaacson et al., 1993; Scanziani, 2000). Because $\mathrm{GABA}_{\mathrm{B}}$ receptors have a high GABA affinity, substantially higher than that of $\mathrm{GABA}_{\mathrm{A}}$ receptors (Chen et al., 1994; Sodickson and Bean, 1996; Mezler et al., 2001), they are well suited to respond to extrasynaptic GABA. As a result, they may see a relatively slower profile of GABA rise and decay than that seen by $\mathrm{GABA}_{\mathrm{A}}$ receptors in the synaptic cleft.

\section{The pattern of $\mathrm{GABA}_{\mathrm{B}}$-mediated inhibition is glomerulus dependent and odor dependent}

As Figure 3 shows, the effect of CGP54626 on PN odor responses is robust and significant when averaged over all experiments. Nevertheless, we noted considerable variability across glomeruli, and across odors, in the effect of $\mathrm{GABA}_{\mathrm{B}}$ blockade. In many PNodor pairs, CGP54626 reduced or abolished inhibitory components of the odor-evoked responses. Figure $4, A$ and $B$, shows this in two different PNs with their dendrites in different glomeruli. In other cell-odor pairs, CGP54626 had little effect on the odor response. Figure 4, $C$ and $D$, shows examples of this from two different cells. The same odor, pentyl acetate, was the stimulus in all four of these examples (Fig. $4 A-D$ ). This implies that an odor can trigger $\mathrm{GABA}_{\mathrm{B}}$-mediated inhibition nonuniformly across the $\mathrm{PN}$ population.

The effect of $\mathrm{GABA}_{\mathrm{B}}$ blockade was also odor dependent. For example, whereas $\mathrm{GABA}_{\mathrm{B}}$ blockade did not affect the response to pentyl acetate of a $\mathrm{PN}$ in glomerulus DM5 (Fig. 4C), it did affect the response of the same PN to methyl salicylate (Fig. $4 E$ ). Also, for a PN in glomerulus VM3, although CGP54626 removed the prolonged inhibition elicited by pentyl acetate (Fig. $4 A$ ), it only affected the early phase of the response to methyl salicylate (Fig. $4 F$ ). Thus, the magnitude and timing of $\mathrm{GABA}_{\mathrm{B}}$-mediated inhibition onto a PN depends on the odor stimulus.

Odor-evoked synaptic inhibition in the antennal lobe and olfactory bulb is thought to amplify the difference between the representations of different odors through several possible mechanisms (Yokoi et al., 1995; Friedrich and Laurent, 2001). We 

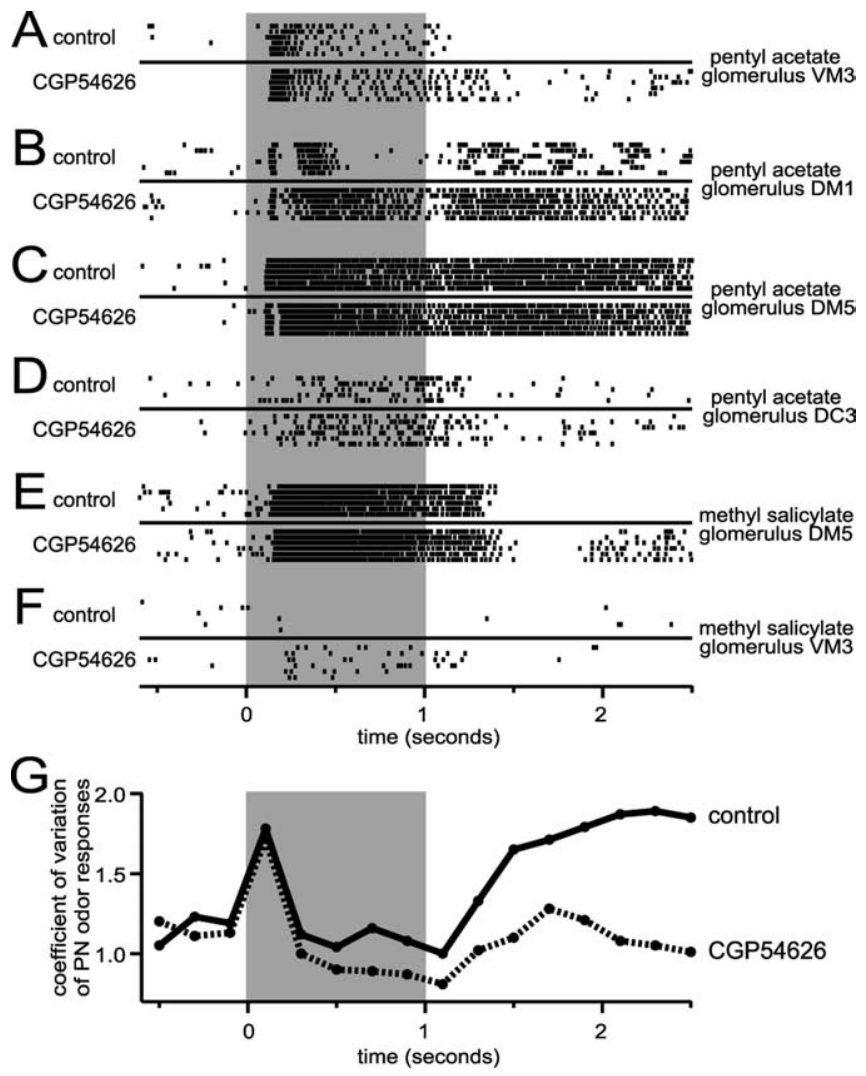

Figure 4. $\quad G_{A B A_{B}}$ receptors mediate odor-dependent, glomerulus-dependent synaptic inhibition. $\boldsymbol{A}-\boldsymbol{F}$, Rasters show spikes in individual PNs before (top) and after (bottom) CGP54626 was added. In many cells $(\boldsymbol{A}, \boldsymbol{B}), \mathrm{GABA}_{\mathrm{B}}$ blockade removed an inhibitory epoch from the odor response. In other cells (C, D), there was little effect. Although CGP54626 did not change the response to pentyl acetate in glomerulus DM5 (C), it did affect the response to methyl salicylate (E). $\boldsymbol{C}$ and $\boldsymbol{E}$ are from the same cell. $\boldsymbol{A}$ and $\boldsymbol{F}$ contrast the effect of CGP54626 on different odor responses in glomerulus VM3. $\boldsymbol{A}$ and $\boldsymbol{F}$ are from the same cell. $\boldsymbol{G}$, The coefficient of variation of the mean PN peristimulus-time histogram shows two peaks (solid line). CGP54626 (dashed line) selectively decreases the second peak, indicating a decrease in the tendency of odor responses to diverge over time. Each CV value is plotted on the $x$-axis in the center of the $200 \mathrm{~ms}$ bin over which it was calculated.

examined the possible contribution of $\mathrm{GABA}_{\mathrm{B}}$-mediated inhibition by comparing the diversity of $\mathrm{PN}$ odor responses across the PN population before and after adding CGP54626. Stimulusevoked responses were recorded from $11 \mathrm{PNs}$ in response to several odors, before and after adding CGP54626 to the bath. Using these data (including the experiments illustrated in Fig. $4 A-F$ ), we constructed a peristimulus-time histogram for each $\mathrm{PN}$-odor combination using $200 \mathrm{~ms}$ time bins. This resulted in 46 histograms, each based on at least six trials. Then, we computed the coefficient of variation $(\mathrm{CV}=\mathrm{SD} /$ mean $)$ across all 46 peristimulus-time histograms, within each time bin. This allowed us to track the degree of divergence in the population of odor responses over time. The CV of the ensemble peaked just after odor onset, fell, and then increased again after pulse offset (Fig. 4G). Blocking $G_{A B A}$ receptors selectively suppressed the late increase in the CV. This result is consistent with the idea that $\mathrm{GABA}_{\mathrm{B}}$-mediated inhibition contributes to a divergent redistribution of activity across the PN ensemble, thus potentially increasing the discriminability of odor representations.

In principle, purely intraglomerular interactions could produce odor-dependent inhibition. In this scenario, local excitation of an LN by a PN triggers feedback inhibition selectively onto that PN. Such local reciprocal circuits mediate inhibition of olfactory bulb mitral cells (Jahr and Nicoll, 1982; Isaacson and Strowbridge, 1998). However, slow $\mathrm{GABA}_{\mathrm{B}}$ inhibitory epochs likely originate, at least in part, from interglomerular circuits. Comparing Figure 4, $C$ and $E$, for example, shows that two odors can evoke very similar initial activation levels in a PN but very different degrees of $\mathrm{GABA}_{\mathrm{B}}$-mediated inhibition later in the response, arguing that the late inhibition in Figure $4 E$ originates from $L N$ activation in other glomeruli.

Although these results show that $\mathrm{GABA}_{\mathrm{B}}$-mediated inhibition is important in generating odor-evoked spatiotemporal patterns in the antennal lobe, other mechanisms also play a role. CGP54626 completely blocked the odor-evoked slow inhibition in about one-half (15 of 29) of all cell-odor combinations in which such inhibition was present. In another one-third of these cases (10 of 29), CGP54626 shortened or diminished an inhibitory epoch but did not abolish it. Figure $4 E$ illustrates one such example. In four cases, CGP54626 had no effect on an inhibitory epoch. We do not at present know what mediates these epochs, but they may represent cases in which the ORNs projecting to this glomerulus are inhibited by the odor (Hallem et al., 2004). In addition, intrinsic inhibitory conductances in PNs might contribute to inhibitory epochs that follow strong excitation. In any event, GABAergic inhibition seems to work together with other mechanisms to produce odor-evoked spatiotemporal patterns of activity in the antennal lobe.

\section{Single local neurons arborize widely but nonuniformly throughout the antennal lobe}

What connectivity scheme produces odor-dependent spatial patterns of GABA release in the antennal lobe? In the mammalian olfactory bulb, there is evidence that an odor stimulus elicits a spatially heterogeneous pattern of inhibition (Luo and Katz, 2001). Individual GABAergic local neurons extend their neurites over only a small fraction of the total olfactory bulb, and presumably this pattern of inhibition reflects their local connectivity. In Drosophila, in contrast, LNs spread their branches throughout the entire sphere of the antennal lobe (Stocker et al., 1990). We therefore reexamined the morphology of single LNs to determine whether the pattern of glomerular innervation of an LN could be heterogeneous and whether the pattern of glomerular connectivity might differ across LNs.

The morphology of single Drosophila antennal lobe LNs has so far been described only on the basis of Golgi impregnations, in which glomerular boundaries are not visible (Stocker et al., 1990). We filled single LNs with biocytin and visualized their morphology with a fluorescent conjugate of streptavidin. Using an antibody (nc82) that stains the antennal lobe neuropil, most glomerular compartments become visible with confocal fluorescence microscopy (Laissue et al., 1999). We could typically identify $\sim 40$ different glomerular compartments in each antennal lobe.

All LNs we filled arborized widely throughout the antennal lobe $(n=13)$. Each LN projected neurites into most glomeruli (Fig. 5A). We do not at present see evidence in Drosophila for so-called "oligoglomerular LNs" (branching sparsely in just a few glomeruli), which have been described in moths (Christensen et al., 1993; Anton and Hansson, 1994). The morphology illustrated in Figure $5 \mathrm{~A}$ was typical of biocytin-filled LNs marked by the enhancer trap lines GH298 $(n=3)$ and c739 $(n=5)$, as well as LNs in wild-type flies $(n=5)$.

Although all LNs branched throughout the antennal lobe, some LNs did not send any branch into one to three glomeruli. These "bypassed" glomeruli often included a cluster of anterolat- 

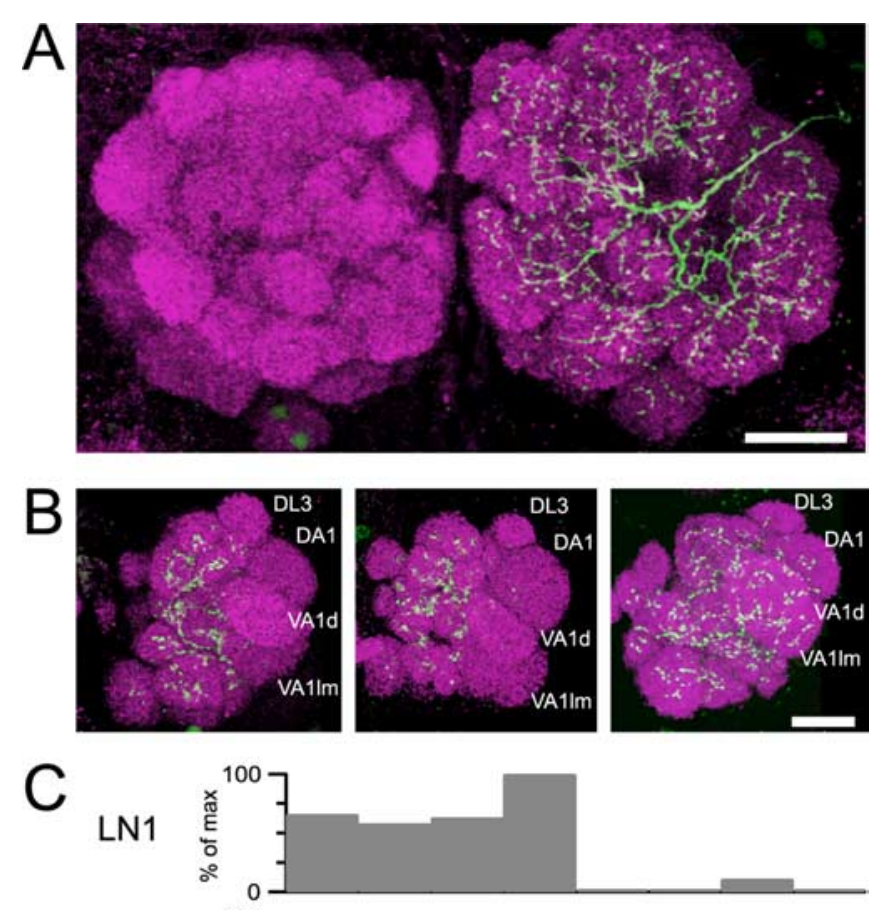

LN2
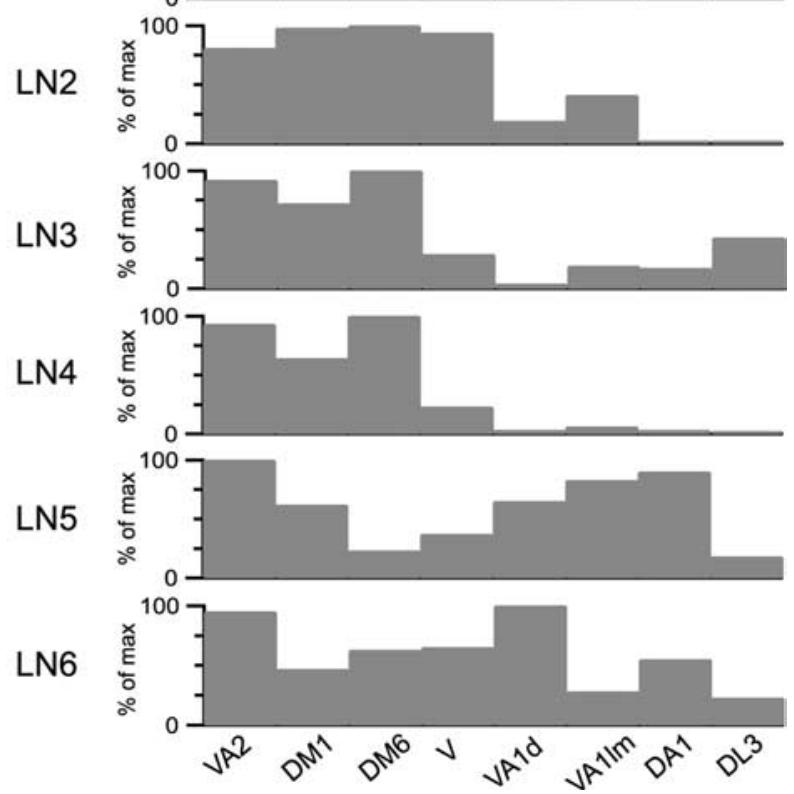

Figure 5. Morphological heterogeneity among multiglomerular LNs. A, Projection of a 15 $\mu \mathrm{m}$ confocal Z-stack through the center of both antennal lobes showing the morphology of a representative $L N$ filled with biocytin. A primary neurite enters the antennal lobes from the lateral side and arborizes throughout many glomeruli. $\boldsymbol{B}$, An example of three different $L N$ s that innervate anterolateral glomeruli to varying degrees. Each image is a projection of a $15 \mu \mathrm{m}$ stack through the most anterior portion of the right antennal lobe. Scale bars: $A, B, 20 \mu \mathrm{m}$. C, The spatial pattern of innervation density varies across different $L$ Ns. Density [as a percentage of the maximum (\% of max) density for that $L N$ ] is plotted for four densely innervated glomeruli (VA2, DM1, DM6, V) and four glomeruli that are more sparsely innervated (VA1d, VA1Im, DA1, DL3).

eral glomeruli (DL3, DA1, VA1d, and VA1lm) and less frequently other glomeruli (e.g., DC3). Figure 5B illustrates two LNs that innervated the anterolateral glomeruli either sparsely or not at all, together with a third LN that innervated all glomeruli more uniformly. These three LNs are reminiscent of types that have been described previously (as "asymmetrical" and "symmetrical multiglomerular LNs," respectively) in other insects (Matsumoto and Hildebrand, 1981; Ernst and Boeckh, 1983; Flanagan and
Mercer, 1989; Christensen et al., 1993; Sun et al., 1993; Anton and Hansson, 1994).

Most glomeruli (other than these frequently bypassed glomeruli) were innervated by each LN. We selected a subset of these typical glomeruli for quantitative analysis, choosing four compartments that are relatively easy to identify (VA2, DM1, DM6, and V). For six LNs, we measured the intensity of the signal from the streptavidin-conjugated fluorophore in each of these glomeruli. We computed the mean intensity of this fluorophore over each glomerulus and normalized each glomerulus to the brightest glomerulus for that cell. This analysis showed a slightly different pattern of arborization for each LN. All six LNs innervated each of these four glomeruli, but the relative weighting of each glomerulus differed across LNs (Fig. 5C). We also measured innervation density in the four atypical anterolateral glomeruli (DL3, DA1, VAld, and VA1lm) and found a lower innervation density for these glomeruli, although again with variation across cells (Fig. 5C).

This suggests that each LN releases GABA widely throughout the antennal lobe but that it does so nonuniformly. Insofar as each glomerulus may contain both presynaptic and postsynaptic LN neurites, this also suggests that single LNs receive a broad, but nonuniform, spatial pattern of excitation.

\section{Heterogeneous odor tuning among local neurons}

Drosophila antennal lobe LNs are broadly tuned to odors (Wilson et al., 2004). Although each LN we analyzed arborized widely throughout most of the antennal lobe, the morphological variation we observed among LNs predicted that LNs may also have individual odor preferences.

We measured odor-evoked activity in six LNs in response to seven odors plus a solvent control (paraffin oil). The eight stimuli were always presented in the same order. Each LN responded with at least a small firing rate increase to every stimulus. In comparison to $\mathrm{PNs}$, LN responses are relatively uniform across odors, both in magnitude and temporal profile (Wilson et al., 2004). However, different LNs did display specific odor preferences, both in terms response magnitude and latency (Fig. 6A). We do not know what aspects of LN spike trains are most salient for postsynaptic $\mathrm{PNs}$, but $\mathrm{GABA}_{\mathrm{B}}$-mediated inhibition is known to depend strongly on the number of presynaptic action potentials (Dutar and Nicoll, 1988; Scanziani, 2000). Therefore, we quantified LN responses simply by counting the total number of spikes elicited by an odor over a $3 \mathrm{~s}$ period after odor pulse onset. We then normalized this to the maximum response elicited in that LN across our seven-odor test set. This analysis showed that some LNs were activated particularly strongly by some odors and more weakly by others (e.g., LN 9) (Fig. 6B). Other LNs were more uniformly responsive (e.g., LN 12). The identity of the stimulus producing the highest firing rates also differed across LNs (Fig. 6B). This suggests that an LN releases more GABA in response to some odors than to others and that the relative level of synaptic inhibition in PNs is both PN and LN dependent. This heterogeneity may be caused by the nonuniform distribution of LN neurites and may account, at least in part, for why blocking GABA receptors can have odor-dependent effects on the activity of single PNs (Fig. 4).

\section{Discussion}

GABAergic inhibition of PNs and LNs via functionally specialized receptor types

The properties of GABAergic neurons have not been described previously in the adult Drosophila antennal lobe, and the cellular effects of GABA have not been investigated in this important 


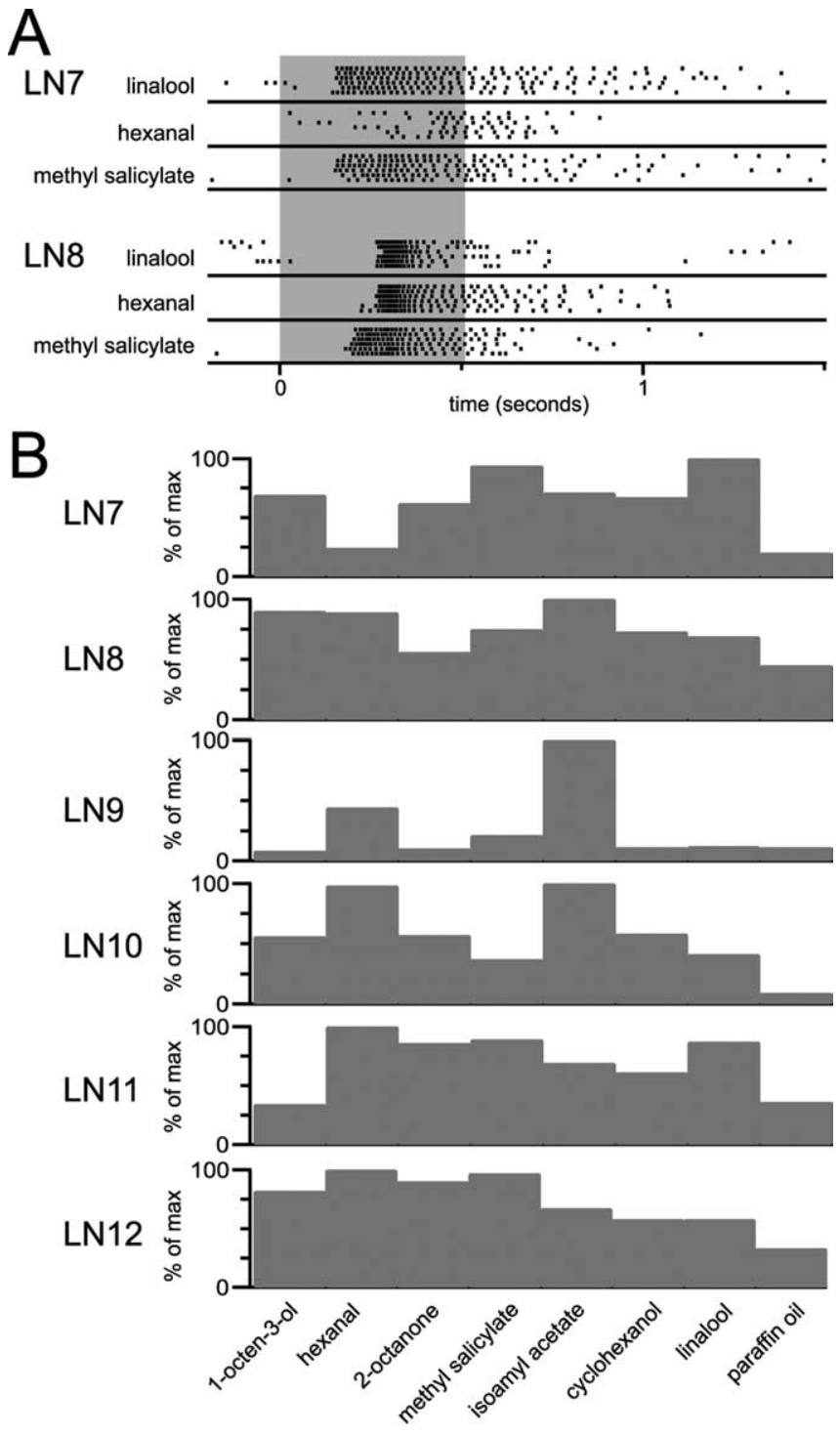

Figure 6. Heterogeneity in odor responses among $L N s$. $\boldsymbol{A}$, Rasters compare the responses of two different LNs (same as cells LN7 and LN8 in $\boldsymbol{B}$ ) with three odors (gray bar; $500 \mathrm{~ms}$ ). The first of these responds more weakly to hexanal than to linalool or methyl salicylate. The second cell responds equally strongly to all three odors, but latency of the methyl salicylate response is shortest. $\boldsymbol{B}, 0$ dor preferences vary across $L N$ s. The number of odor-evoked spikes [as a percentage of the maximum (\% of max) response for each cell] is plotted for each odor.

olfactory model system. Here, we have begun to address these questions using a combination of electrophysiology, pharmacology, immunocytochemistry, and genetic cell markers. We found that most LNs labeled by the enhancer trap line GH298 are GABA immunopositive, whereas most PNs (labeled by GH146) are not. Next, we confirmed that GABA hyperpolarizes antennal lobe neurons. In LNs, our results imply that inhibition is mediated entirely by $\mathrm{GABA}_{\mathrm{A}}$ receptors. In contrast, GABAergic inhibition of $\mathrm{PNs}$ is mediated by both $\mathrm{GABA}_{\mathrm{A}}$ and $\mathrm{GABA}_{\mathrm{B}}$ receptors. Thus, synaptic inhibition onto PNs and LNs is functionally specialized.

\section{Role of $\mathrm{GABA}_{\mathrm{B}}$ receptors in odor-evoked temporal patterns in PNs}

How might GABAergic inhibition contribute to olfactory processing in the Drosophila antennal lobe? Recent studies using optical measurements of neural activity have concluded that ORN and $\mathrm{PN}$ odor responses are very similar and that the antennal lobe is merely a relay station that faithfully transmits ORN signals to PNs without alteration (Ng et al., 2002; Wang et al., 2003). These conclusions imply that synaptic inhibition in the antennal lobe may exist merely to control global excitability and may not play an important role in representing information about the stimulus. However, the optical reporters used in these studies lack temporal resolution, have limited dynamic range, and may not be sensitive to inhibitory events (Sankaranarayanan and Ryan, 2000; Pologruto et al., 2004). Whole-cell patch-clamp recordings from Drosophila PNs show prominent inhibitory epochs in many odor responses, generating odor-dependent spatiotemporal response patterns (Wilson et al., 2004). Such complex temporal patterns are not present in the responses of ORNs (de Bruyne et al., 1999; de Bruyne et al., 2001), implying that they arise in the antennal lobe and thus represent a transformation of the olfactory code between the first and second layers of olfactory processing. These temporal patterns are reminiscent of those seen in olfactory bulb mitral cells (Meredith, 1986; Hamilton and Kauer, 1989; Wellis et al., 1989; Buonviso et al., 1992; Friedrich and Laurent, 2001; Luo and Katz, 2001) and in other insects (MacLeod and Laurent, 1996; Christensen et al., 1998; Perez-Orive et al., 2002).

A common notion in olfaction is that such spatiotemporal patterns represent lateral interactions, the net effect of which is to amplify contrast. This idea has taken two main forms. The first proposes a contrast-enhancement mechanism akin to that seen in the retina. According to this model, specific mutual inhibitory interactions exist between principal neurons in nearby glomeruli with similarly tuned ORN inputs. When a principal neuron is activated strongly by an odor, it will trigger lateral inhibition of its neighbors to suppress weak responses to that odor, sharpening the difference between their tuning curves (Yokoi et al., 1995; Uchida et al., 2000). A different hypothesis is that lateral interactions exist in a more distributed manner. Odors are represented as stimulus-specific sequences of neuronal ensembles. The stimulus is represented both by the identity of the active neurons and the time when they are active. According to this model, the net effect of interglomerular interactions is not to prune away weak responses. Rather, inhibitory interactions may coexist with excitatory interactions (or relief-of-inhibition mechanisms), such that new principal neuron responses appear as others disappear. Because each stimulus is represented by an evolving neural ensemble, the available coding space is expanded. Again, the outcome of this process is thought to be a progressive decorrelation, such that overlap is reduced between stimulus representations (Friedrich and Laurent, 2001, 2004; Stopfer et al., 2003).

Both these models predict that eliminating odor-evoked inhibitory epochs in second-order olfactory neurons will increase the similarity between the spatiotemporal activity patterns produced in these neurons by different odors. Here, we report that odor-evoked inhibitory epochs in Drosophila PNs are mostly suppressed by a $\mathrm{GABA}_{\mathrm{B}}$ receptor antagonist and that blocking $\mathrm{GABA}_{\mathrm{B}}$ receptors decreases the coefficient of variation among PN peristimulus-time histograms. These results are consistent with models in which lateral interactions between principal and local neurons increase the degree of difference between the neural representations of different odors.

It is important to point out that the effect of the $\mathrm{GABA}_{\mathrm{B}}$ antagonist on $\mathrm{PN}$ odor responses may be mediated partly by presynaptic effects on ORN axon terminals (Wachowiak and Cohen, 1999; Aroniadou-Anderjaska et al., 2000) or by indirect effects via other excitatory inputs to PNs. Determining the locus of this effect will require additional experiments using cell type-specific 
genetic manipulations. However, because $\mathrm{GABA}_{\mathrm{B}}$ receptors mediate much of the direct effect of GABA on PNs, it seems likely that the effect of CGP54626 on odor-evoked PN activity is attributable at least in part to postsynaptic $\mathrm{GABA}_{\mathrm{B}}$ receptors.

Finally, we should note that two conceptually distinct kinds of temporal patterns can in principle coexist among second-order olfactory neurons. Slow temporal patterns are punctuated by inhibitory epochs on the timescale of tens to thousands of milliseconds. In this study, we have shown that these slow patterns in the Drosophila antennal lobe are sensitive to a $\mathrm{GABA}_{\mathrm{B}}$ antagonist. Distinct from this is fast inhibition, which synchronizes the firing of principal neurons on time scales of several milliseconds and is sensitive to picrotoxin (MacLeod and Laurent, 1996). Fast, odorevoked synchronous oscillations occur in the olfactory systems of many organisms (Adrian, 1942; Bressler and Freeman, 1980; Gray and Skinner, 1988; Gelperin and Tank, 1990; Laurent and Davidowitz, 1994; Lam et al., 2000; Friedrich and Laurent, 2001) and are required for fine olfactory discrimination in the honeybee (Stopfer et al., 1997) and mollusk (Teyke and Gelperin, 1999). There is little evidence for such oscillatory synchronization among Drosophila PNs (R. I. Wilson, unpublished observations; G. C. Turner, personal communication). These observations deserve additional investigation but suggest that different organisms may emphasize different strategies for olfactory processing.

\section{Odor-dependent spatial heterogeneity in GABAergic inhibition}

Theoretical models of olfactory processing that invoke synaptic inhibition to increase the contrast between different stimulus representations presume nonuniform connectivity between inhibitory and principal neurons (Bazhenov et al., 2001; Urban, 2002; Linster et al., 2005). In insects, a GABAergic LN can arborize across the entire antennal lobe, and so it is not obvious that single LNs will make connections preferentially with particular glomeruli. In this study, we found that the neurites of single LNs form spatially heterogeneous patterns in the antennal lobe. This finding alone does not prove that individual LNs make connections preferentially in the glomeruli in which their dendrites are most dense; for example, average synaptic strength could be higher in glomeruli with fewer neurites. However, individual LNs also displayed specific odor preferences. This supports the idea that the odor tuning of individual LNs might be correlated with which glomeruli were preferentially innervated by that LN. According to this model, LN odor tuning would be biased toward the tuning of the excitatory neurons innervating those glomeruli. Drosophila LNs receive excitatory input from PNs (Wilson et al., 2004). In other insect species, LNs are also known to receive direct input from ORNs (Distler, 1990).

Consistent with these conclusions, a functional imaging study of the Drosophila antennal lobe has found that each odor stimulus evokes GABA release in some glomeruli more than others. Furthermore, these spatial patterns of GABA release are odor dependent (Ng et al., 2002). That study measured synaptic release from all GABAergic neurons simultaneously. We have now extended this investigation to single LNs, the morphological and functional diversity of which suggests a cellular mechanism for how the pattern of GABA release can be nonuniform and odor dependent. Ultimately, a test of this idea should come from correlating the morphology of single LNs with their odor preferences. Recent studies have reported the odor tuning of a large subset of Drosophila olfactory receptors and the mapping of each receptor to a specific ORN type (Hallem et al., 2004; Goldman et al., 2005). Once we know which ORN type corresponds to each glomerulus, it should be possible to design experiments of this type more systematically.

\section{References}

Adrian ED (1942) Olfactory reactions in the brain of the hedgehog. J Physiol (Lond) 100:459-473.

Anton S, Hansson BS (1994) Central processing of sex pheromone, host odour, and oviposition deterrent information by interneurons in the antennal lobe of female Spodoptera littoralis (Lepidoptera: Noctuidae). J Comp Neurol 350:199-214.

Aroniadou-Anderjaska V, Zhou FM, Priest CA, Ennis M, Shipley MT (2000) Tonic and synaptically evoked presynaptic inhibition of sensory input to the rat olfactory bulb via GABA(B) heteroreceptors. J Neurophysiol 84:1194-1203.

Bazhenov M, Stopfer M, Rabinovich M, Abarbanel HD, Sejnowski TJ, Laurent G (2001) Model of cellular and network mechanisms for odorevoked temporal patterning in the locust antennal lobe. Neuron 30:569-581.

Bicker G (1999) Histochemistry of classical neurotransmitters in antennal lobes and mushroom bodies of the honeybee. Microsc Res Tech 45:174-183.

Bressler SL, Freeman WJ (1980) Frequency analysis of olfactory system EEG in cat, rabbit, and rat. Electroencephalogr Clin Neurophysiol 50:19-24.

Buonviso N, Chaput MA, Berthommier F (1992) Temporal pattern analyses in pairs of neighboring mitral cells. J Neurophysiol 68:417-424.

Cang J, Isaacson JS (2003) In vivo whole-cell recording of odor-evoked synaptic transmission in the rat olfactory bulb. J Neurosci 23:4108-4116.

Celentano JJ, Wong RK (1994) Multiphasic desensitization of the GABAA receptor in outside-out patches. Biophys J 66:1039-1050.

Chen R, Belelli D, Lambert JJ, Peters JA, Reyes A, Lan NC (1994) Cloning and functional expression of a Drosophila gamma-aminobutyric acid receptor. Proc Natl Acad Sci USA 91:6069-6073.

Christensen TA, Waldrop BR, Harrow ID, Hildebrand JG (1993) Local interneurons and information processing in the olfactory glomeruli of the moth Manduca sexta. J Comp Physiol A Neuroethol Sens Neural Behav Physiol 173:385-399.

Christensen TA, Waldrop BR, Hildebrand JG (1998) Multitasking in the olfactory system: context-dependent responses to odors reveal dual GABA-regulated coding mechanisms in single olfactory projection neurons. J Neurosci 18:5999-6008.

de Bruyne M, Clyne PJ, Carlson JR (1999) Odor coding in a model olfactory organ: the Drosophila maxillary palp. J Neurosci 19:4520-4532.

de Bruyne M, Foster K, Carlson JR (2001) Odor coding in the Drosophila antenna. Neuron 30:537-552.

Distler P (1990) GABA-immunohistochemistry as a label for identifying types of local interneurons and their synaptic contacts in the antennal lobes of the American cockroach. Histochemistry 93:617-626.

Dobritsa AA, van der Goes van Naters W, Warr CG, Steinbrecht RA, Carlson JR (2003) Integrating the molecular and cellular basis of odor coding in the Drosophila antenna. Neuron 37:827-841.

Dutar P, Nicoll RA (1988) A physiological role for GABAB receptors in the central nervous system. Nature 332:156-158.

Ernst KD, Boeckh J (1983) A neuroanatomical study on the organization of the central antennal pathways in insects. III. Neuroanatomical characterization of physiologically defined response types of deutocerebral neurons in Periplaneta americana. Cell Tissue Res 229:1-22.

ffrench-Constant RH, Mortlock DP, Shaffer CD, MacIntyre RJ, Roush RT (1991) Molecular cloning and transformation of cyclodiene resistance in Drosophila: an invertebrate gamma-aminobutyric acid subtype A receptor locus. Proc Natl Acad Sci USA 88:7209-7213.

Flanagan D, Mercer AR (1989) Morphology and response characteristics of neurons in the deutocerebrum of the brain in the honeybee Apis mellifera. J Comp Physiol A Neuroethol Sens Neural Behav Physiol 164:483-494.

Friedrich RW, Laurent G (2001) Dynamic optimization of odor representations by slow temporal patterning of mitral cell activity. Science 291:889-894.

Friedrich RW, Laurent G (2004) Dynamics of olfactory bulb input and output activity during odor stimulation in zebrafish. J Neurophysiol 91:2658-2669.

Gelperin A, Tank DW (1990) Odour-modulated collective network oscillations of olfactory interneurons in a terrestrial mollusc. Nature 345:437-440. 
Goldman AL, van der Goes van Naters W, Lessing D, Warr CG, Carlson JR (2005) Coexpression of two functional odor receptors in one neuron. Neuron 45:661-666.

Gray CM, Skinner JE (1988) Centrifugal regulation of neuronal activity in the olfactory bulb of the waking rabbit as revealed by reversible cryogenic blockade. Exp Brain Res 69:378-386.

Hallem EA, Carlson JR (2004) The odor coding system of Drosophila. Trends Genet 20:453-459.

Hallem EA, Ho MG, Carlson JR (2004) The molecular basis of odor coding in the Drosophila antenna. Cell 117:965-979.

Hamasaka Y, Wegener C, Nässel DR (2005) GABA modulates Drosophila circadian clock neurons via GABAB receptors and decreases in calcium. J Neurobiol, in press.

Hamilton KA, Kauer JS (1989) Patterns of intracellular potentials in salamander mitral/tufted cells in response to odor stimulation. J Neurophysiol 62:609-625.

Harrison JB, Chen HH, Sattelle E, Barker PJ, Huskisson NS, Rauh JJ, Bai D, Sattelle DB (1996) Immunocytochemical mapping of a C-terminus anti-peptide antibody to the GABA receptor subunit, RDL in the nervous system in Drosophila melanogaster. Cell Tissue Res 284:269-278.

Harvey RJ, Schmitt B, Hermans-Borgmeyer I, Gundelfinger ED, Betz H, Darlison MG (1994) Sequence of a Drosophila ligand-gated ion-channel polypeptide with an unusual amino-terminal extracellular domain. J Neurochem 62:2480-2483.

Henderson JE, Soderlund DM, Knipple DC (1993) Characterization of a putative gamma-aminobutyric acid (GABA) receptor beta subunit gene from Drosophila melanogaster. Biochem Biophys Res Commun 193:474-482.

Hollins B, McClintock TS (2000) Lobster GABA receptor subunit expressed in neural tissues. J Neurosci Res 59:534-541.

Hosie AM, Aronstein K, Sattelle DB, ffrench-Constant RH (1997) Molecular biology of insect neuronal GABA receptors. Trends Neurosci 20:578-583.

Hoskins SG, Homberg U, Kingan TG, Christensen TA, Hildebrand JG (1986) Immunocytochemistry of GABA in the antennal lobes of the sphinx moth Manduca sexta. Cell Tissue Res 244:243-252.

Isaacson JS, Strowbridge BW (1998) Olfactory reciprocal synapses: dendritic signaling in the CNS. Neuron 20:749-761.

Isaacson JS, Solis JM, Nicoll RA (1993) Local and diffuse synaptic actions of GABA in the hippocampus. Neuron 10:165-175.

Jahr CE, Nicoll RA (1982) An intracellular analysis of dendrodendritic inhibition in the turtle in vitro olfactory bulb. J Physiol (Lond) 326:213-234.

Kanzaki R, Arbas EA, Strausfeld NJ, Hildebrand JG (1989) Physiology and morphology of projection neurons in the antennal lobe of the male moth Manduca sexta. J Comp Physiol Physiol A Neuroethol Sens Neural Behav Physiol 165:427-453.

Keller A, Vosshall LB (2003) Decoding olfaction in Drosophila. Curr Opin Neurobiol 13:103-110.

Laissue PP, Reiter C, Hiesinger PR, Halter S, Fischbach KF, Stocker RF (1999) Three-dimensional reconstruction of the antennal lobe in Drosophila melanogaster. J Comp Neurol 405:543-552.

Lam YW, Cohen LB, Wachowiak M, Zochowski MR (2000) Odors elicit three different oscillations in the turtle olfactory bulb. J Neurosci 20:749-762.

Laurent G, Davidowitz H (1994) Encoding of olfactory information with oscillatory neural assemblies. Science 265:1872-1875.

Lee D, Su H, O'Dowd DK (2003) GABA receptors containing Rdl subunits mediate fast inhibitory synaptic transmission in Drosophila neurons. J Neurosci 23:4625-4634.

Leitch B, Laurent G (1996) GABAergic synapses in the antennal lobe and mushroom body of the locust olfactory system. J Comp Neurol 372:487-514.

Linster C, Sachse S, Galizia CG (2005) Computational modeling suggests that response properties rather than spatial position determine connectivity between olfactory glomeruli. J Neurophysiol 93:3410-3417.

Luo M, Katz LC (2001) Response correlation maps of neurons in the mammalian olfactory bulb. Neuron 32:1165-1179.

MacLeod K, Laurent G (1996) Distinct mechanisms for synchronization and temporal patterning of odor-encoding neural assemblies. Science 274:976-979.
Macrides F, Chorover SL (1972) Olfactory bulb units: activity correlated with inhalation cycles and odor quality. Science 175:84-87.

Malun D (1991) Synaptic relationships between GABA-immunoreactive neurons and an identified uniglomerular projection neuron in the antennal lobe of Periplaneta americana: a double-labeling electron microscopic study. Histochemistry 96:197-207.

Margrie TW, Sakmann B, Urban NN (2001) Action potential propagation in mitral cell lateral dendrites is decremental and controls recurrent and lateral inhibition in the mammalian olfactory bulb. Proc Natl Acad Sci USA 98:319-324.

Marin EC, Jefferis GS, Komiyama T, Zhu H, Luo L (2002) Representation of the glomerular olfactory map in the Drosophila brain. Cell 109:243-255.

Matsumoto SG, Hildebrand JG (1981) Olfactory mechanisms in the moth Manduca sexta: response characteristics and morphology of central neurons in the antennal lobes. Proc R Soc Lond B Biol Sci 213:249-277.

Meredith M (1986) Patterned response to odor in mammalian olfactory bulb: the influence of intensity. J Neurophysiol 56:572-597.

Mezler M, Muller T, Raming K (2001) Cloning and functional expression of GABA(B) receptors from Drosophila. Eur J Neurosci 13:477-486.

Murphy VF, Wann KT (1988) The action of GABA receptor agonists and antagonists on muscle membrane conductance in Schistocerca gregaria. Br J Pharmacol 95:713-722.

Ng M, Roorda RD, Lima SQ, Zemelman BV, Morcillo P, Miesenbock G (2002) Transmission of olfactory information between three populations of neurons in the antennal lobe of the fly. Neuron 36:463-474.

Perez-Orive J, Mazor O, Turner GC, Cassenaer S, Wilson RI, Laurent G (2002) Oscillations and sparsening of odor representations in the mushroom body. Science 297:359-365.

Pologruto TA, Yasuda R, Svoboda K (2004) Monitoring neural activity and $\left[\mathrm{Ca}^{2+}\right]$ with genetically encoded $\mathrm{Ca}^{2+}$ indicators. J Neurosci 24:9572-9579.

Python F, Stocker RF (2002) Immunoreactivity against choline acetyltransferase, gamma-aminobutyric acid, histamine, octopamine, and serotonin in the larval chemosensory system of Drosophila melanogaster. J Comp Neurol 453:157-167.

Ressler KJ, Sullivan SL, Buck LB (1993) A zonal organization of odorant receptor gene expression in the olfactory epithelium. Cell 73:597-609.

Ressler KJ, Sullivan SL, Buck LB (1994) Information coding in the olfactory system: evidence for a stereotyped and highly organized epitope map in the olfactory bulb. Cell 79:1245-1255.

Rohrbough J, Broadie K (2002) Electrophysiological analysis of synaptic transmission in central neurons of Drosophila larvae. J Neurophysiol $88: 847-860$.

Sachse S, Galizia CG (2002) Role of inhibition for temporal and spatial odor representation in olfactory output neurons: a calcium imaging study. J Neurophysiol 87:1106-1117.

Sankaranarayanan S, Ryan TA (2000) Real-time measurements of vesicleSNARE recycling in synapses of the central nervous system. Nat Cell Biol 2:197-204.

Sattelle DB, Pinnock RD, Wafford KA, David JA (1988) GABA receptors on the cell-body membrane of an identified insect motor neuron. Proc R Soc Lond B Biol Sci 232:443-456.

Scanziani M (2000) GABA spillover activates postsynaptic GABA(B) receptors to control rhythmic hippocampal activity. Neuron 25:673-681.

Sodickson DL, Bean BP (1996) GABA $_{B}$ receptor-activated inwardly rectifying potassium current in dissociated hippocampal CA3 neurons. J Neurosci 16:6374-6385.

Stocker RF, Lienhard MC, Borst A, Fischbach KF (1990) Neuronal architecture of the antennal lobe in Drosophila melanogaster. Cell Tissue Res 262:9-34.

Stocker RF, Heimbeck G, Gendre N, de Belle JS (1997) Neuroblast ablation in Drosophila P[GAL4] lines reveals origins of olfactory interneurons. J Neurobiol 32:443-456.

Stopfer M, Bhagavan S, Smith BH, Laurent G (1997) Impaired odour discrimination on desynchronization of odour-encoding neural assemblies. Nature 390:70-74.

Stopfer M, Jayaraman V, Laurent G (2003) Intensity versus identity coding in an olfactory system. Neuron 39:991-1004.

Su H, O’Dowd DK (2003) Fast synaptic currents in Drosophila mushroom body Kenyon cells are mediated by $\alpha$-bungarotoxin-sensitive nicotinic acetylcholine receptors and picrotoxin-sensitive GABA receptors. J Neurosci 23:9246-9253. 
Sun XJ, Fonta C, Masson C (1993) Odour quality processing by bee antennal lobe interneurons. Chem Senses 18:355-377.

Teyke T, Gelperin A (1999) Olfactory oscillations augment odor discrimination not odor identification by Limax CNS. NeuroReport 10:1061-1068.

Uchida N, Takahashi YK, Tanifuji M, Mori K (2000) Odor maps in the mammalian olfactory bulb: domain organization and odorant structural features. Nat Neurosci 3:1035-1043.

Urban NN (2002) Lateral inhibition in the olfactory bulb and in olfaction. Physiol Behav 77:607-612.

Vassar R, Ngai J, Axel R (1993) Spatial segregation of odorant receptor expression in the mammalian olfactory epithelium. Cell 74:309-318.

Vassar R, Chao SK, Sitcheran R, Nunez JM, Vosshall LB, Axel R (1994) Topographic organization of sensory projections to the olfactory bulb. Cell 79:981-991.

Vosshall LB, Amrein H, Morozov PS, Rzhetsky A, Axel R (1999) A spatial map of olfactory receptor expression in the Drosophila antenna. Cell 96:725-736.
Vosshall LB, Wong AM, Axel R (2000) An olfactory sensory map in the fly brain. Cell 102:147-159.

Wachowiak M, Cohen LB (1999) Presynaptic inhibition of primary olfactory afferents mediated by different mechanisms in lobster and turtle. J Neurosci 19:8808-8817.

Wang JW, Wong AM, Flores J, Vosshall LB, Axel R (2003) Two-photon calcium imaging reveals an odor-evoked map of activity in the fly brain. Cell 112:271-282.

Wellis DP, Scott JW, Harrison TA (1989) Discrimination among odorants by single neurons of the rat olfactory bulb. J Neurophysiol 61:1161-1177.

Wilson RI, Turner GC, Laurent G (2004) Transformation of olfactory representations in the Drosophila antennal lobe. Science 303:366-370.

Yokoi M, Mori K, Nakanishi S (1995) Refinement of odor molecule tuning by dendrodendritic synaptic inhibition in the olfactory bulb. Proc Natl Acad Sci USA 92:3371-3375.

Zhang HG, Lee HJ, Rocheleau T, ffrench-Constant RH, Jackson MB (1995) Subunit composition determines picrotoxin and bicuculline sensitivity of Drosophila gamma-aminobutyric acid receptors. Mol Pharmacol 48:835-840. 